\title{
Robustness of timber structures in seismic areas
}

Jorge M. Branco ${ }^{1}$ and Luis A.C. Neves ${ }^{2}$

\section{Introduction}

Some of the properties sought in seismic design of buildings are also considered fundamental to guarantee structural robustness. Moreover, some key concepts are common to both seismic and robustness design. In fact, both analyses consider events with a very small probability of occurrence, and consequently, a significant level of damage is admissible. As very rare events, in both cases, the actions are extremely hard to quantify. The acceptance of limited damage requires a system based analysis of structures, rather than an element by element methodology, as employed for other load cases.

As for robustness analysis, in seismic design the main objective is to guarantee that the structure survives an earthquake, without extensive damage. In the case of seismic design, this is achieved by guaranteeing the dissipation of energy through plastic hinges distributed in the structure. For this to be possible, some key properties must be assured, in particular ductility and redundancy.

The same properties could be fundamental in robustness design, as a structure can only sustain significant damage if capable of distributing stresses to parts of the structure unaffected by the triggering event.

Timber is often used for primary load-bearing elements in single storey long-span structures for public buildings and arenas, where severe consequences can be expected if one or more of the primary load bearing elements fail. The structural system used for these structures consists of main frames, secondary elements and bracing elements. The main frame, composed by columns and beams, can be seen as key elements in the system and should be designed with high safety against failure and under strict quality control. The main frames may sometimes be designed with moment resisting joints between columns and beams. Scenarios, where one or more of these key elements, fail should be considered at least for high consequence buildings. Two alternative strategies may be applied: isolation of collapsing sections and, provision of alternate load paths [1]. The first one is relatively straightforward to provide by deliberately designing the secondary structural system less strong and stiff. Alternatively, the secondary structural system and the bracing system can be design so that loss of capacity in the main frame does not lead to the collapse. A case study has been selected aiming to assess the consequences of these two different strategies, in particular, under seismic loads.

\footnotetext{
${ }^{1}$ Assistant Professor, ISISE, Department of Civil Engineering, University of Minho, Portugal

${ }^{2}$ Assistant Professor, UNIC, Department of Civil Engineering, New University of Lisbon, Portugal
} 


\section{Earthquake design}

Similarly to other seismic design codes, the EN 1998-1:2004 [2] state that, in order to obtain structures resistant to earthquakes, the following aspects must be considered: structural simplicity; uniformity, symmetry and redundancy; bi-directional resistance and stiffness; torsional resistance and stiffness; diaphragmatic behavior at the storey level; and, adequate foundations.

A clear and direct path for the transmission of the seismic forces is available in simple structures, while uniformity allows the inertial forces created in the distributed masses of the building to be transmitted via short and direct paths. Redundancy allows a more favorable redistribution of action effects and widespread energy dissipation across the entire structure. A basic goal of a seismic design is the establishment of diaphragmatic action of the horizontal load bearing systems and the connection (anchorage of the diaphragms) to the vertical load bearing components (walls or frames) in order to transfer the seismic forces to the most rigid ones and tie the whole building.

The choice of the methods of analysis depends on the structure and the objective of the analysis: linear static analysis (termed the "lateral force" method of analysis in EN 19981:2004); modal response spectrum analysis (also termed in practice "linear dynamic); nonlinear static analysis (commonly known as "pushover" analysis); and, non-linear dynamic analysis (time-history or response-history analysis).

Most earthquake design codes provide an acceleration response spectrum curve that specifies the design acceleration (defining a horizontal load) based on the natural period of the structure. The basic principle of EN 1998-1:2004 [2] is that when the structure presents a ductile behavior, the design acceleration and the horizontal force imposed to the building is reduced by division by the so called behavior factor $q$. The behavior factor $q$ is an approximation of the ratio of the internal forces that the structure would experience if its response was completely elastic, to those that may be considered in the design to ensure a satisfactory response of the structure. The behavior factor is affected by several parameters such as ductility, overstrength and redundancy reduction factors.

\section{Timber structures under seismic loads}

Satisfactory performance of timber buildings, in general, can be partially attributed to the material characteristics of wood itself, and to the lightness and high redundancy of most wood-based structural systems. The lateral redundancy plays an important role in seismic performance of timber structures. A redundant design will almost certainly offer more parallel load paths that can transmit the applied lateral loading on the building down to the foundation. The detailing of connections is very important because the more integrated and interconnected the structure is, the more load distribution possibilities there are. The building's structural integrity is only as good as the weakest link in the load transmission path and, as a consequence, good performance expectations are contingent on appropriate design, quality workmanship and proper maintenance. 
For timber structures, EN 1998-1:2004 [2] presents upper limit values of the behavior factor depending on the ductility class, on the structural type (essentially reflecting the greater or lesser redundancy of the structure as a whole) and on the nature of the structural connections (essentially reflecting its ductility and energy dissipation capacity). Semi-rigid and rigid connections are normally associated with the distinction between dissipative and lowdissipative structures, respectively.

EN 1998-1:2004 [2] proposes a classification of timber structures in Ductility Class Medium (DCM) and Ductility Class High (DCH) for dissipative structures and Ductility Class Low (DCL) in the case of non-dissipative structures. Besides the general upper limit of $q=1.5$ for DCL accounting for overstrength, for DCM and DCH the values indicated for $q$ in Table 8.1 of EN 1998-1:2004 [2] are reproduced in Table 1 with a different arrangement that highlights the influence of the various parameters on the ductility of timber structures (namely the superior behavior of correctly designed and executed nailed connections).

Table 1 - Maximum values of the behavior factor $q$ for timber structures of DCM and DCH

\begin{tabular}{lll}
\hline Structural type & DCM & DCH \\
\hline $\begin{array}{l}\text { Wall panels with glued diaphragms } \\
\text { connected with nails and bolts }\end{array}$ & Glued wall panels & Nailed wall panels \\
$\begin{array}{l}\text { Wall panels with nailed diaphragms } \\
\text { connected with nails and bolts }\end{array}$ & $\mathrm{q}=2.0$ & $\mathrm{q}=3.0$ \\
Trusses & & Nailed panels \\
Mixed structures with timber framing and & $\mathrm{q}=5.0$ \\
non-load-bearing infills & $\mathrm{q}=2.0$ & Nailed joints \\
$\begin{array}{l}\text { Hyperstatic portal frame with doweled and } \\
\text { bolted joints }\end{array}$ & $\mu \geq 4$ & $\mathrm{q}=3.0$ \\
\hline
\end{tabular}

NOTE: $\mu$ is the static ductility ratio.

\section{Seismic design and robustness}

To analyze the influence of seismic design in the robustness of structures is it fundamental to define the main strategies to improve robustness. In general, robustness can be improved by reducing the probability of damage, reducing the probability of failure if damage occurs, or by reducing the cost of failure. In the second case, it is paramount to define alternative load paths and to guarantee that: (i) enough resistance exists in these paths to prevent failure; (ii) enough ductility exists to guarantee these paths can be mobilized. If the improvement in robustness is to be achieved through reduction in cost associated with partial failures, then compartmentalization is crucial. In this case, load paths must be cut, in order to limit the extent of failure.

The philosophy of designing to limit the spread of damage rather than to prevent damage entirely is different from the traditional approach to designing to withstand dead, live, snow, and wind loads, but is similar to the philosophy adopted in modern earthquake-resistant design [3]. 
The guiding principles for a good conceptual design for earthquake resistant buildings have a significant influence on the robustness of structures. In fact, structural simplicity, uniformity, symmetry and redundancy are fundamental in the existence of alternate load paths, a key concept in robustness design.

Above all, the seismic design leads to an improvement in ductility and redundancy, as well as ensuring the interconnection of the structure. As a consequence, if a structure is designed according to existing seismic codes, a significant improvement to its resistance in the event of damage might be achieved. On the other hand, the increased redundancy and removal of weak links between elements and parts of the structure will allow damage to propagate through the structure, leading to higher costs in the event of failure.

In the particular case of timber structures, seismic design requires a much closer attention to detailing of connections. This can, indirectly, provide enhanced robustness since a significant number of observed failures are associated with errors in connections between elements.

Lastly, the consideration of earthquakes in some regions has lead to significant evolution of engineering practice, leading to significant differences in common practice between countries were earthquakes are likely to occur, if only over long time periods, and those where they are not considered in design. Some of these practices can have a large effect on the robustness of structures, in particular, timber structures.

A clear example of this is the use of strong column - weak beam concept in designing buildings, common for seismic resistance. In seismic areas, columns are usually continuous elements, and beams are connected to column at each span. This situation guarantees that key elements, as the columns, are capable of sustaining additional loads, and failure will occur in the beams. This will limit progressive collapse to a single floor and to a bay. If, on the other hand, strong beams or continuous beam are used, failure will progress from bay to bay, increasing the affected area and, consequently, failure costs.

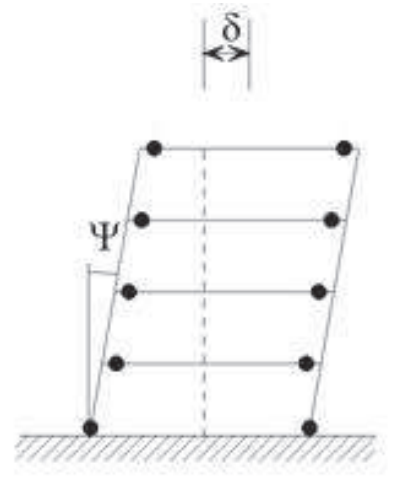

a) Weak beams

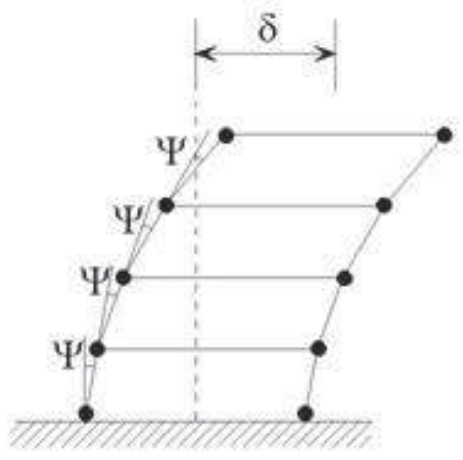

b) Strong beams

Figure 1 - Strong column - weak beam concept 


\section{Eurocode 8 and robustness prescriptive rules}

At present, few existing codes present significant prescriptive rules to improve robustness of structures. However, there are some general rules identified to have positive influence on the robustness, namely: (i) selective "overstrength" (strong column/weak beam concept); (ii) redundancy (e.g. by providing alternative paths for loads shed from damaged elements); (iii) ductility of response (e.g. by adopting members and connections that can absorb significant strain energy without rupture or collapse).

Analyzing the EN 1998-1:2004 [2] provisions, in particular the ones specific to timber structures, several can be pointed out as measures to enhance robustness:

- $\quad[8.6(4)]$ In order to ensure the development of cyclic yielding in the dissipative zones, all other structural members and connections shall be designed with sufficient overstrength. This overstrength requirement applies especially to: anchor-ties and any connections to massive sub-elements; and, connections between horizontal diaphragms and lateral load resisting vertical elements;

- $\quad$ 4.2.1.2(5)] The use of evenly distributed structural elements increases redundancy and allows a more favorable redistribution of action effects and widespread energy dissipation across the entire structure;

- $\quad$ 5.2.3.5(1)] A high degree of redundancy accompanied by redistribution capacity shall be sought, enabling a more widely spread energy dissipation and an increased total dissipated energy. Consequently structural systems of lower static indeterminacy shall be assigned lower behavior factors;

- $\quad$ 2.2.4.1 (2)P] In order to ensure an overall dissipative and ductile behavior, brittle failure or the premature formation of unstable mechanisms shall be avoided. To this end, where required in the relevant Parts of EN 1998-1:2004, resort shall be made to the capacity design procedure, which is used to obtain the hierarchy of resistance of the various structural components and failure modes necessary for ensuring a suitable plastic mechanism and for avoiding brittle failure modes.

Using the capacity design method it is possible, by choosing certain modes of deformation, to ensure that brittle elements have the capacity to remain intact, while the inelastic deformations occur in selected ductile elements. These "fuses" or energy absorbers act as dampers to reduce force level in the structure [4]. In timber structures the ductility is concentrated in the joints whereas the timber elements must be regarded as behaving elastically. Therefore, a reliable strength prediction of the joint and its components is essential for applying the capacity design and ensuring the required ductility. This is the possible explanation for the absence of EN 1998-1:2004 [2] provisions for the capacity design method application to the case of timber structures. 


\section{Examples}

In this section, several examples of failures are analyzed and the foreseeable influence of considering seismic design on the outcome will be evaluated.

The first example is the Ronan Point Building failure, triggered by a gas explosion. In this prefabricated structure, the consequences of the explosion were amplified by poor workmanship and very limited connection between elements. The existence of strong links between elements is a central requirement in seismic design, and, had earthquake loading been considered, a different, more redundant, structure would have been erected. In principle, this would have reduced the impact of the explosion, limiting the indirect costs associated to the incident.

The Alfred Murrah Federal Building collapsed following the explosion of a car bomb parked in the basement. The building had a structural system composed of regular frames, but, at the ground level, the number of columns was reduced, as shown in Figure 2. This structural system lead to an increase in consequences of the explosion, and could have been avoided, had the building been analyzed in a seismic design perspective. In fact, the soft first story failure is prevented by the seismic design. Corley et al. [5] pointed out that more than $50 \%$ of the collapsed area would have stood if the structure had been designed with special moment frames found in seismic regions as opposed to the ordinary moment frames used in the building.

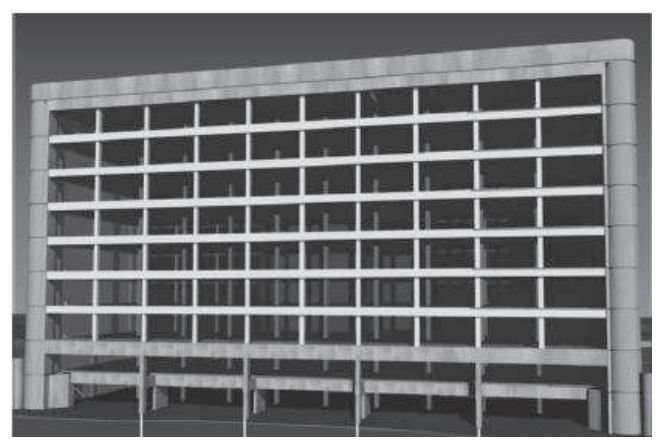

Figure 2 - Alfred Murrah Federal Building structure

In 1993, a car bomb exploded in the parking lot under world Trade Centre building, causing a significant local damage with a cost of $\$ 300,000,000$. However, the redundant structure, supported by numerous smaller columns, rather than a central nucleus, significantly reduced the consequences of damages, and no important indirect damages resulted from the explosion.

At the beginning of the year 2006, $2^{\text {nd }}$ January, the ice-arena roof in Bad Reichenhall collapsed under the actual snow load (Figure 3). Fifteen people died, thirty were partly or heavily injured. The main reasons for the collapse are: (i) use of urea-formaldehyde glue under moist conditions; (ii) mistakes in the static calculation; (iii) non robust construction; and, (iv) lack of maintenance. According to the findings of experts Winter and Kreuzinger [6], one of the three main box-girders on the east side failed first. Due to the stiff cross girders, the loads were shifted from the box-girder that failed first to the neighboring girders. These box-girders, 
which were already pre-damaged were also overloaded due to which the entire roof collapse like a zipper. This transversal stiffness is, however, a desirable property under seismic design, and no real advantage could have been obtained from considering earthquake as a load. In fact, as shown in Figure 3 an increase in stiffness of transversal elements can, in fact, lead to an increased risk associated with damage.

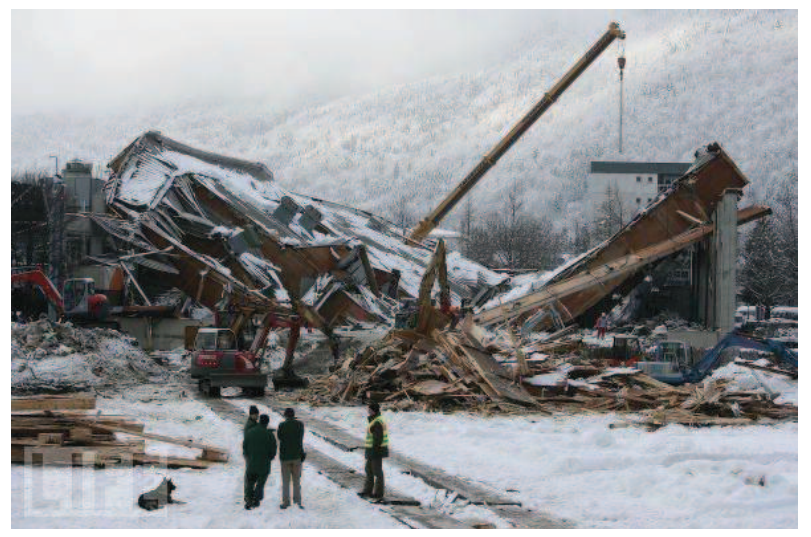

Figure 3 - Bad Reichenhall ice-arena collapse

In the case of the Siemens Arena failure (Figure 4), the first consequence of a seismic design would have been the increase of transversal stiffness. This could have caused progressive failure, following the collapse of one truss, leading to large increase in indirect consequences of damage. In fact, the $12 \mathrm{~m}$ long purlins between the trusses were only moderately fastened, such that a failure of one truss should not initiate progressive collapse. As all trusses had much lower strength than required by the failure of a neighbor element, it might be fair to conclude that the extent of the collapse was not disproportionate to the cause, as analyzed by Munch-Andersen [7]. The result of a seismic design could have been an increase in transversal stiffness, which could have caused progressive collapse of the structure.

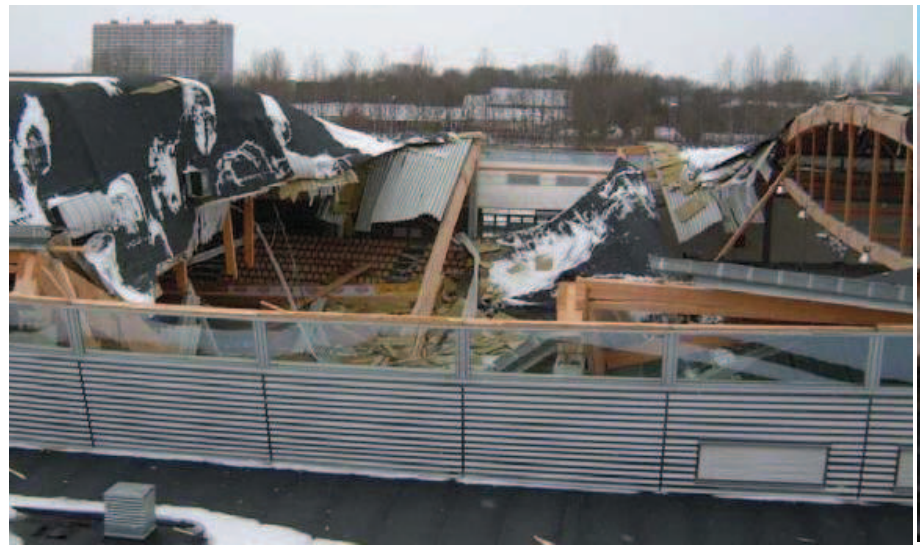

a) An intact truss is seen to the right

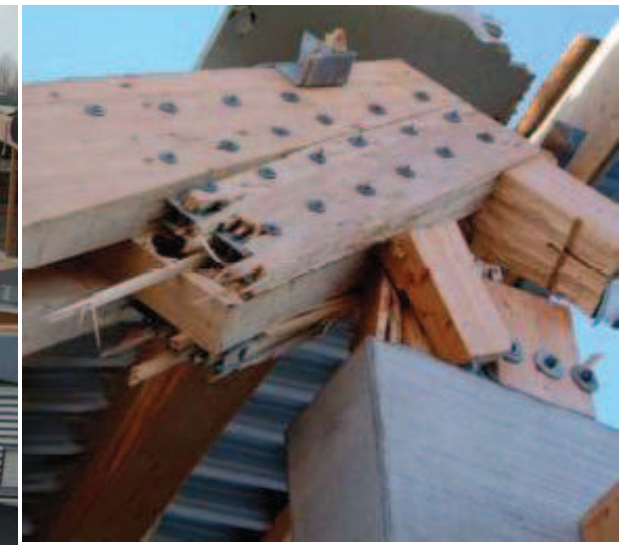

b) Rupture at the critical cross section in the corner connection

Figure 4 - Siemens Arena roof after the collapse of two trusses Munch-Andersen [7]

In these last two cases, the only possible advantage of seismic design would have been the closer attention paid to the detailing of connections, required for the definition of the 
dissipation zones defined in EN 1998-1:2004. In fact, connections played a major role in both incidents, and a more careful design could have avoided the errors.

\section{Case study}

A case study has been selected aiming to assess the consequences of redundancy and ductility on the robustness of long-span timber roof structures under seismic loads. The structure selected, with $35.33 \times 40.00 \mathrm{~m}^{2}$, is composed by main frames with a free span of $32.83 \mathrm{~m}$, spaced 5 meters. The secondary structure is composed by purlins, spaced $1.25 \mathrm{~m}$, in one case with 5 meters length, connecting two main frames, and in another with 10 meters length, connecting three main frames. Figure 5 presents the main frame, materialized by a three-hinge portal frame, and some details of the connections.
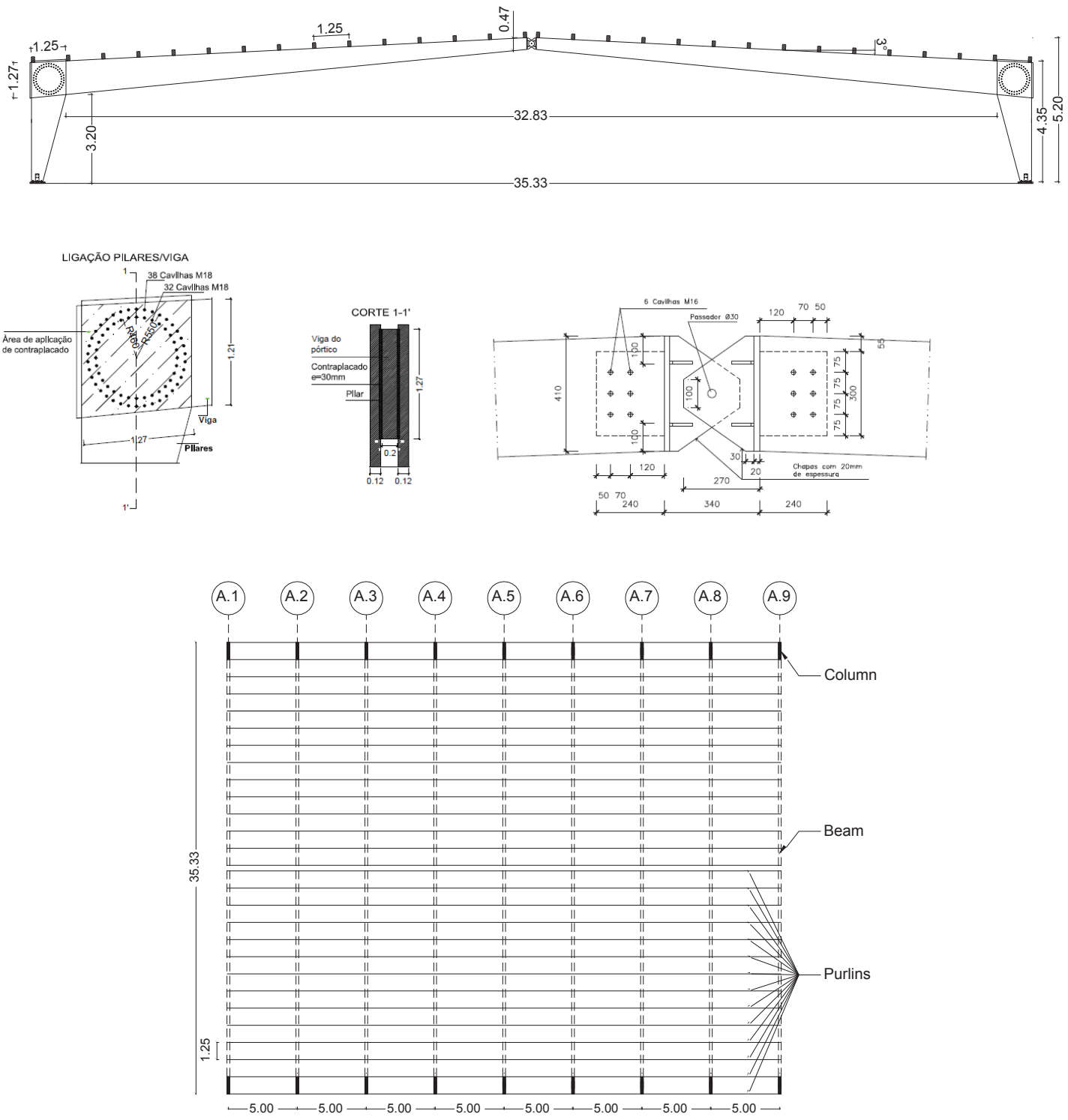

Figure 5 - Main frame and details of the connections 
In a first step, different damage scenarios have been considered and the effect of each of these has been assessed. This analysis was made using the combination of actions for accidental situations. Only two scenarios showed to have significance: (S1) failure of one column and, (S2) failure of the central hinge-joint. In fact, the stiffness of the connections, in particular, of the moment resisting column-beam connection, even for a reduction of $75 \%$ (S3), does not affect the structural safety.

The arrangement of the secondary structural system (purlins) is crucial in the overall behavior. As mentioned, two hypotheses were considered for the purlins: simple supported beams with $5 \mathrm{~m}$ length and double span with $10 \mathrm{~m}$. Table 2 presents the safety verification for ultimate limit states defined by Eurocode 5 (EN 1995-1:2004) [8], for the undamaged situation and for the scenarios adopted, considering continuous and very resistant purlins, and assuming damage in frame 3. The shaded values, corresponding to failure, show that frame 2 and 4 become unsafe when damage occurs in the column or central hinge of frame 3 .

Table 2 - Safety verification for different damage scenarios

\begin{tabular}{|c|c|c|c|c|c|}
\hline Frame & Section & Undamaged & $\begin{array}{c}\mathrm{S} 1 \\
\text { (Column) }\end{array}$ & $\begin{array}{c}\text { S2 } \\
\text { (Central hinge-joint) }\end{array}$ & $\begin{array}{c}\text { S3 } \\
(0,25 \text { joint stiffness })\end{array}$ \\
\hline \multirow{8}{*}{2} & 1 & 0.28 & 0.45 & 0.53 & 0.58 \\
\hline & 2 & 0.05 & 0.09 & 0.10 & 0.07 \\
\hline & 3 & 0.31 & 0.56 & 0.58 & 0.42 \\
\hline & 4 & 0.31 & 0.86 & 1.02 & 0.54 \\
\hline & 5 & 0.31 & 0.86 & 1.02 & 0.54 \\
\hline & 6 & 0.34 & 0.74 & 0.63 & 0.46 \\
\hline & 7 & 0.48 & 1.06 & 0.89 & 0.66 \\
\hline & 8 & 0.39 & 0.93 & 0.71 & 0.80 \\
\hline \multirow{8}{*}{3} & 1 & 0.30 & 0.65 & 0.91 & 0.64 \\
\hline & 2 & 0.46 & 0.52 & 0.39 & 0.66 \\
\hline & 3 & 0.32 & 0.35 & 0.26 & 0.46 \\
\hline & 4 & 0.25 & 0.12 & $* * *$ & 0.39 \\
\hline & 5 & 0.25 & 0.12 & $* * *$ & 0.39 \\
\hline & 6 & 0.35 & 0.00 & 0.29 & 0.50 \\
\hline & 7 & 0.50 & 0.00 & 0.44 & 0.71 \\
\hline & 8 & 0.41 & 0.01 & 0.73 & 0.86 \\
\hline \multirow{8}{*}{4} & 1 & 0.29 & 0.46 & 0.54 & 0.63 \\
\hline & 2 & 0.45 & 0.82 & 0.85 & 0.65 \\
\hline & 3 & 0.32 & 0.57 & 0.59 & 0.46 \\
\hline & 4 & 0.25 & 0.72 & 0.89 & 0.39 \\
\hline & 5 & 0.25 & 0.72 & 0.90 & 0.39 \\
\hline & 6 & 0.35 & 0.75 & 0.64 & 0.50 \\
\hline & 7 & 0.49 & 1.07 & 0.91 & 0.71 \\
\hline & 8 & 0.40 & 0.93 & 0.72 & 0.85 \\
\hline
\end{tabular}

$* * *$ - section where damage is assumed

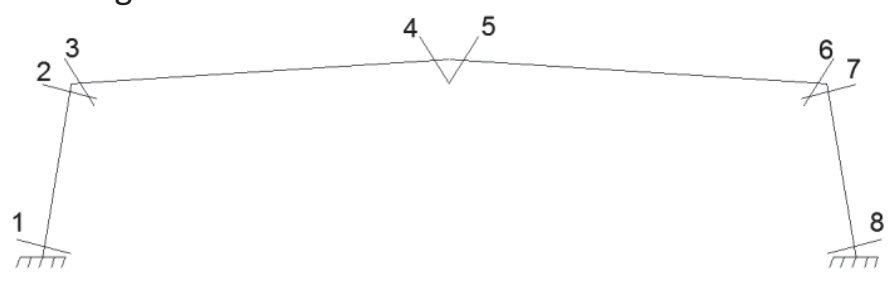


These results show that very stiff and resistant purlins cause the progression of damage to the adjacent frames, resulting in progressive collapse of the overall structure. On the other hand, if less resistant or simple supported purlins are considered, the failure of frame 3 is unavoidable. However, damage will not progress, and consequences will be rather limited.

With the goal to assess the influence of ductility in the overall behavior, two distinct ductility classes were adopted: DCL and DCM, Low and Medium Ductility Class, respectively. The structure as defined can be classified as DCL. However, following the recommendations of EN1998-1:2004, it is possible to upgrade this structure to DCM by increasing the slenderness of the fasteners in the dissipative zones (connections), assuming a fasteners diameter to element thickness ratio higher than 8 . Considering the fasteners diameter $(d)$ of $18 \mathrm{~mm}$, the cross section of the column ( $t$ ) had to be increased to $180 \mathrm{~mm}$ (Figure 6).

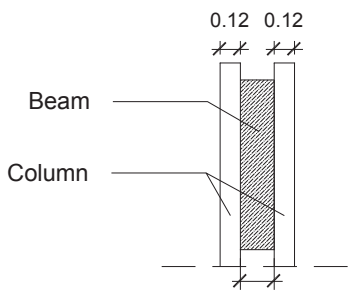

0.20

DCL

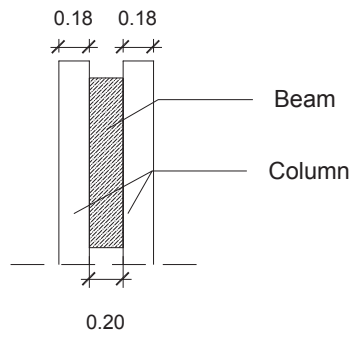

DCM

Figura 6 - Detail of the moment - resisting connections between the column and the beam

As expected, the update design corresponding to DCM results in a higher structural safety when both damage scenarios ( $\mathrm{S} 1$ and S2) are considered. This improvement is more significant in the case of $\mathrm{S} 1$ (failure of the column), Table 3.

Table 3 - Safety verification for damage scenario S1 and different ductility class

\begin{tabular}{|c|c|c|c|c|c|}
\hline \multirow{3}{*}{ Frame } & \multirow{2}{*}{ Section } & \multicolumn{2}{|c|}{ DCL } & \multicolumn{2}{c|}{ DCM } \\
\cline { 2 - 6 } & & Undamaged & S1 & Undamaged & S1 \\
\hline \multirow{5}{*}{2} & 1 & 0.28 & 0.45 & 0.23 & 0.26 \\
\cline { 2 - 6 } & 2 & 0.05 & 0.09 & 0.05 & 0.07 \\
\cline { 2 - 6 } & 3 & 0.31 & 0.56 & 0.44 & 0.57 \\
\cline { 2 - 6 } & 4 & 0.31 & 0.86 & 0.45 & 0.84 \\
\cline { 2 - 6 } & 5 & 0.31 & 0.86 & 0.45 & 0.84 \\
\cline { 2 - 6 } & 6 & 0.34 & 0.74 & 0.49 & 0.74 \\
\cline { 2 - 6 } & 7 & 0.48 & 1.06 & 0.47 & 0.72 \\
\hline \multirow{5}{*}{3} & 8 & 0.39 & 0.93 & 0.33 & 0.54 \\
\hline & 1 & 0.30 & 0.65 & 0.24 & 0.44 \\
\cline { 2 - 6 } & 2 & 0.46 & 0.52 & 0.46 & 0.35 \\
\cline { 2 - 6 } & 3 & 0.32 & 0.35 & 0.47 & 0.35 \\
\cline { 2 - 6 } & 5 & 0.25 & 0.12 & 0.36 & 0.12 \\
\cline { 2 - 6 } & 6 & 0.25 & 0.12 & 0.36 & 0.11 \\
\cline { 2 - 6 } & 7 & 0.35 & 0.00 & 0.51 & 0.00 \\
\cline { 2 - 6 } & 8 & 0.50 & 0.00 & 0.50 & 0.00 \\
\hline 4 & 1 & 0.29 & 0.01 & 0.35 & 0.01 \\
\hline
\end{tabular}




\begin{tabular}{|l|l|l|l|l|l|}
\hline & 2 & 0.45 & 0.82 & 0.45 & 0.56 \\
\cline { 2 - 6 } & 3 & 0.32 & 0.57 & 0.46 & 0.58 \\
\cline { 2 - 6 } & 4 & 0.25 & 0.72 & 0.36 & 0.71 \\
\cline { 2 - 6 } & 5 & 0.25 & 0.72 & 0.36 & 0.71 \\
\cline { 2 - 6 } & 6 & 0.35 & 0.75 & 0.50 & 0.75 \\
\cline { 2 - 6 } & 7 & 0.49 & 1.07 & 0.49 & 0.73 \\
\cline { 2 - 6 } & 8 & 0.40 & 0.93 & 0.34 & 0.54 \\
\hline
\end{tabular}

In the particular case of the analyzed timber structure, the ductility class has no influence on the dynamic properties. The modes shape and the natural frequency remains similar when the structure is updated from DCL to DCM for both arrangements of the secondary structure (Table 4). A slight difference is observed in the fundamental frequency and corresponding mode shape between the single and double span purlins (Figure 7). This fact results from the lower stiffness, in the longitudinal direction of the roof, in the first case.

Table 4 - Dynamic properties of the structures considering different ductility class and secondary structure arrangement

\begin{tabular}{|c|c|c|c|c|c|c|c|c|}
\hline \multirow{2}{*}{ Mode shape } & \multicolumn{4}{|c|}{ DCL } & \multicolumn{4}{c|}{ DCM } \\
\cline { 2 - 9 } & \multicolumn{2}{|c|}{ Period (s) } & \multicolumn{2}{|c|}{ Frequency $(\mathrm{Hz})$} & \multicolumn{2}{c|}{ Period (s) } & \multicolumn{2}{c|}{ Frequency (Hz) } \\
\hline 1 & 1.66 & 1.76 & 0.60 & 0.57 & 1.59 & 1.68 & 0.63 & 0.59 \\
\hline 2 & 0.75 & 0.75 & 1.33 & 1.33 & 0.73 & 0.73 & 1.37 & 1.37 \\
\hline 3 & 0.49 & 0.49 & 2.03 & 2.04 & 0.48 & 0.48 & 2.05 & 2.05 \\
\hline Purlins & $\mathrm{D}$ & $\mathrm{S}$ & $\mathrm{D}$ & $\mathrm{S}$ & $\mathrm{D}$ & $\mathrm{S}$ & $\mathrm{D}$ & $\mathrm{S}$ \\
\hline
\end{tabular}

D - Double span purlins; $S$ - Single span purlins.

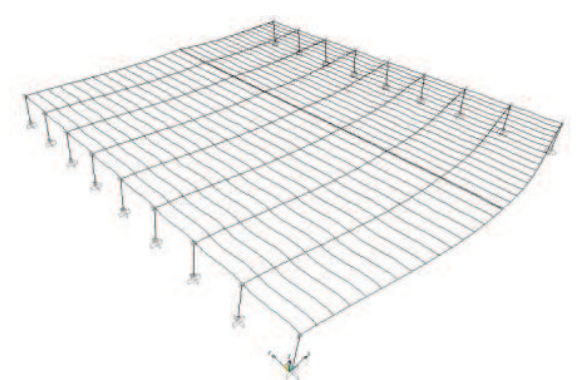

a) 1st mode shape, double span purlins

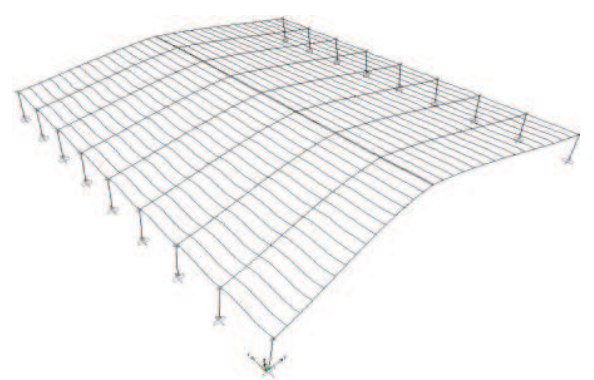

d) 1st mode shape, single span purlins

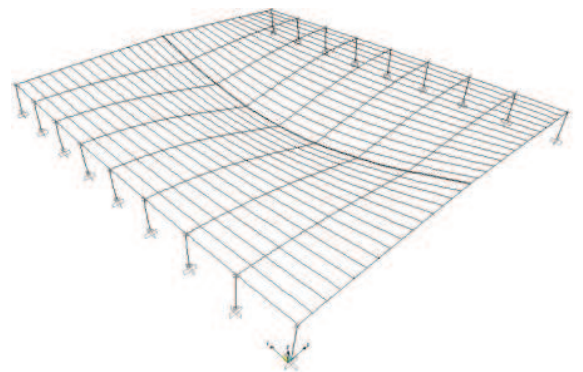

b) 2nd mode shape, double span purlins

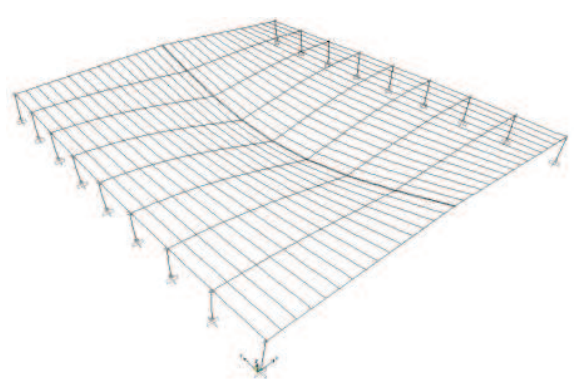

e) 2nd mode shape, single span purlins

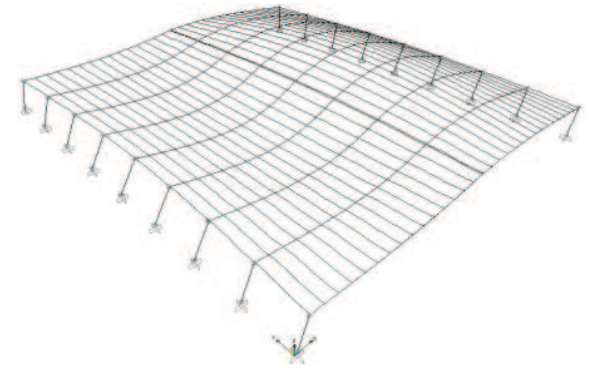

c) 3rd mode shape, double span purlins

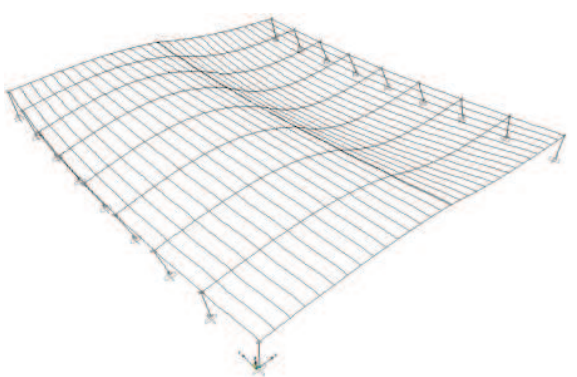

f) 3rd mode shape, single span purlins

Figure 7 - Modes shape of the structure for different arrangement of the secondary structure 
Figure 8 presents the acceleration response spectrum curve obtained for the structure, considering the structure located in Lisbon, Portugal, for DCL and DCM, in the case of double span purlins. It is possible to confirm that the good dynamic properties recognized to timber structures, associated with low natural frequencies, results in a small value of the design acceleration (Sa).

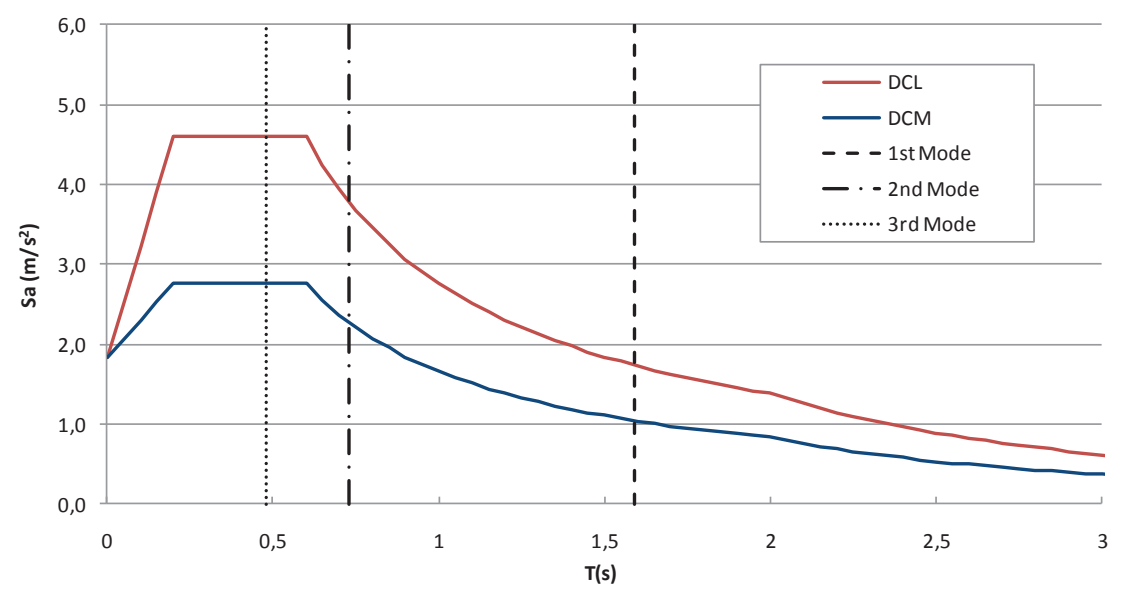

Figure 8 - Acceleration response spectrum curve

Moreover, the ductility class has also little influence on the baseline shear (Table 5), despite the difference between the design acceleration values $\left(1.7 \mathrm{~m} / \mathrm{s}^{2}\right.$ and $1.0 \mathrm{~m} / \mathrm{s}^{2}$ for DCL and DCM, respectively) as consequence of the small mass loads mobilized by the seismic combination of loads (Gk + 0.6Qk).

Table 5 - Baseline shear values $(\mathrm{kN})$

\begin{tabular}{|c|c|c|}
\hline Purlins & DCL & DCM \\
\hline Double span & 2281 & 2183 \\
\hline Single span & 2263 & 2168 \\
\hline
\end{tabular}

In terms of safety verification under the seismic loading, higher ductility classes are associated with safer structures (Table 6). Not only the value of the horizontal seismic load decreases but also the modification in the column cross-section implemented to upgrade the ductility class of the structure, increases stiffness and strength of the main frame. The vertical component of the seismic load, in the case of lightweight structures like the timber ones, can be negligible (Table 6).

Table 6 - Safety verification considering horizontal and vertical acceleration response spectrum curve isolated and combined, adopting the two ductility classes analyzed (Frame 3).

\begin{tabular}{|c|c|c|c|c|c|c|}
\hline Sections & \multicolumn{3}{|c|}{ DCL } & \multicolumn{3}{c|}{ DCM } \\
\hline & Horizontal & Vertical & Combination & Horizontal & Vertical & Combination \\
\hline 1 & 0.33 & 0.31 & 0.33 & 0.19 & 0.18 & 0.19 \\
\hline 2 & 0.41 & 0.41 & 0.40 & 0.28 & 0.28 & 0.28 \\
\hline 3 & 0.29 & 0.28 & 0.29 & 0.29 & 0.28 & 0.29 \\
\hline 4 & 0.22 & 0.20 & 0.22 & 0.22 & 0.20 & 0.21 \\
\hline
\end{tabular}




\begin{tabular}{|l|l|l|l|l|l|l|}
\hline 5 & 0.22 & 0.20 & 0.22 & 0.21 & 0.20 & 0.21 \\
\hline 6 & 0.29 & 0.28 & 0.29 & 0.29 & 0.28 & 0.29 \\
\hline 7 & 0.41 & 0.41 & 0.40 & 0.28 & 0.28 & 0.28 \\
\hline 8 & 0.32 & 0.31 & 0.32 & 0.18 & 0.18 & 0.18 \\
\hline
\end{tabular}

The displacements of the structures under seismic loads are important to assess the possible level of damage caused by earthquakes. The arrangement of the secondary structural system in double span purlins results in smaller displacement in the longitudinal direction of the roof while increases the displacements values in the transversal direction (Table 7).

Table 7 - Displacement values for different arrangement of the secondary structure and distintc ductility class

\begin{tabular}{|c|c|c|c|c|c|c|c|}
\hline & & \multicolumn{3}{|c|}{$\mathrm{DCL}$} & \multicolumn{3}{c|}{ DCM } \\
\hline Purlins & Point & $\mathrm{Ux}(\mathrm{mm})$ & $\mathrm{Uy}(\mathrm{mm})$ & $\mathrm{Uz}(\mathrm{mm})$ & $\mathrm{Ux}(\mathrm{mm})$ & $\mathrm{Uy}(\mathrm{mm})$ & $\mathrm{Uz}(\mathrm{mm})$ \\
\hline $\begin{array}{c}\text { Double } \\
\text { span }\end{array}$ & 1 & -21.145 & -1.028 & 1.935 & -19.436 & -0.298 & 1.905 \\
\cline { 2 - 8 } & 2 & 1.381 & 32.755 & -296.563 & 0.839 & 17.998 & -280.649 \\
\hline $\begin{array}{c}\text { Single } \\
\text { span }\end{array}$ & 1 & -20.443 & -1.202 & 1.884 & -18.792 & -0.339 & 1.85 \\
\cline { 2 - 8 } & 2 & -1.268 & -37.641 & -287.867 & -0.768 & -20.59 & -272.197 \\
\hline
\end{tabular}

Point 1 corresponds to the joint column-beam; Point 2 to the connection beam-beam

Moreover, a damage limitation requirement proposed by EN1998-1:2004 consists in the limitation of the interstorey drifts. It is important to point out that, for all structural models considered, with different arrangements of the secondary structure system and two distinct ductility classes, this requirement is fulfill.

\section{Conclusions}

In this paper, the advantages in robustness obtained through a detailed seismic analysis are studied. It is shown that the main prescriptions for an adequate seismic performance tend to improve robustness, mostly due to increase redundancy and ductility. Moreover, it is shown that the requirements for ductility for timber structures are relatively simplistic, and limited to the joints, due to the brittle failure of timber elements. Several examples of failures associated with disproportionate consequences are analyzed and the potential benefits of a seismic design are highlighted. It is shown that, for buildings, a seismic design tends to improve robustness. However, increased redundancy can also lead to an increase in failure cost as a result of a localized damage. This is particularly true for long span timber roof structures. As shown in the case study, a more redundant roof structure is safer to a seismic event but more prone to progressive collapse. 


\section{References}

[1] Thelandersson S. and Honfi D. (2009), Behaviour and modelling of timber structures with reference to robustness. Proceedings of the Joint Workshop of Cost Actions TU0601 and E55. Editors: Jochen Köhler, Harikrishna Narasimhan and Michael H. Faber. September 21-22, Ljubljana, Slovenia, 125-138.

[2] EN 1998-1:2004, Design of structures for earthquake resistance - Part 1: General rules, seismic actions and rules for buildings. European Committee for Standardization, Brussels.

[3] FEMA (2002), NEHRP recommended provisions for the development of seismic regulation for new buildings and other structures. FEMA Rep. No. 368, Federal Emergency Management Agency, Washington,D.C.

[4] Thelandersson S. and Larsen H.J. (2003), Timber Engineering. John Wiley \& Sons, LTD.

[5] Corley W.G., Sozen M.A., Thornton C.H. and Mlakar P.F. (1996), The Oklahoma City Bombing: Improving Building Performance through Multi-Hazard Mitigation. Federal Emergency Management Agency Mitigation Directorate, FEMA Report 277.

[6] Winter S. and Kreuzinger H. (2008), The Bad Reichenhall ice-arena collapse and the necessary consequences for wide span timber structures. Proceedings WCTE 2008 Conference. Miyazaki, Japan.

[7] Munch-Andersen J. (2009), The Siemens Arena collapse in a robustness perspective. COST E 55. 5th Workshop - WG3-Robustness of Systems, Trondheim, Norway.

[8] EN 1995-1-1:2004, Design of timber structures - Part 1-1: General - Common rules and rules for buildings. European Committee for Standardization, Brussels. 